Elisabeth F. Van Gessel MD, * Bernard Miege MD, * Alain Forster MD,* Galice Salvaj MD,* Marc Fathi PhD, $\dagger$ Zdravko Gamulin MD*

\title{
Comparison of hyperbaric solutions of bupivacaine and tetra-
caine during continuous bupivacaine and tetra-
caine during continuous spinal anaesthesia
}

The aim of this study was to compare two equipotent solutions of hyperbaric bupivacaine and tetracaine in 30 elderly patients undergoing elective hip surgery under continuous spinal anaesthesia. With the patient in the supine position, $2 \mathrm{ml}(8 \mathrm{mg})$ of either hyperbaric solution (density 1.030) were administered in a double-blind and randomized fashion. The median maximum sensory and temperature discrimination levels $\left(T_{5}\right.$ and $\left.T_{4}\right)$ were similar with both solutions. The duration of analgesia was not different (114 \pm 23 min for bupivacaine and $125 \pm 35$ min for tetracaine). Thirteen out of fifteen patients receiving bupivacaine and all 15 patients receiving tetracaine had complete motor blockade. The haemodynamic changes and vasopressor requirements were comparable. The plasma catecholamine levels measured at four different times remained unchanged and were not different between the two groups at any time. The authors conclude that, during continuous spinal anaesthesia, equipotent hyperbaric solutions of bupivacaine and tetracaine have similar anaesthetic and haemodynamic effects.

Le but de cette étude était de comparer deux solutions équipotentes de tetracaine et de bupivacaine hyperbares, chez 30 patients agés devant subir une chirurgie de la hanche en rachi-

\section{Key words}

ANAESTHETIC TECHNIQUES: continuous spinal, hyperbaric;

ANAESTHETICS: local, bupivacaine, tetracaine.

From the Department of Anaesthesiology* and Clinical

Laboratory $\dagger$ of the University Hospital, 1211 Geneva

4-Switzerland.

Presented in part at the annual meeting of the American Society of Anesthesiologists, New Orleans, Louisiana, October 1989.

Address correspondence to: Dr. E. Van Gessel, Department of Anaesthesiology, University Hospital of Geneva, 1211 Geneva 4, Switzerland.

Accepted for publication 28th December, 1991. anesthésie continue. Chaque patient, en position horizontale stricte, a reçu en double-aveugle et de façon randomisée $2 \mathrm{ml}(8$ mg) d'une de deux solutions (densité 1,030). Aucune différence $n$ 'a été notée entre les deux groupes en ce qui concerne la valeur médiane des niveaux sensitifs et de discrimination thermique supérieurs $\left(T_{5}\right.$ et $\left.T_{4}\right)$. La durée de l'analgésie $(114 \pm 23 \mathrm{~min}$. pour la bupivacaine et $125 \pm 35$ min. pour la tetracaine) était semblable dans les deux groupes. Treize patients sur les $15 \mathrm{du}$ groupe bupivacaine et tous les 15 patients du groupe tetracaine avaient un bloc moteur complet. Les modifications hémodynamiques ainsi que les besoins en vasopresseurs ont été comparables dans les deux groupes. Les taux de catécholamines plasmatiques, mesurés à quatre moments différents de l'étude, sont restés stables et semblables dans les deux groupes à chaque temps. Les auteurs concluent que lorsqu'on compare la bupivacaine et la tetracaine hyperbares au cours d'une anesthésie spinale continue, les solutions équipotentes de ces deux drogues possèdent des effets anesthésiques et hémodynamiques similaires.

Hyperbaric solutions of bupivacaine and tetracaine have often been compared at identical volumes and dosages using single-shot spinal anaesthesia. ${ }^{1-5}$ Although the global anaesthetic effects of these two drugs have been found to be comparable, clinical differences have been observed.

Tetracaine at a dose of $7.5 \mathrm{mg}^{1,2}$ or $15 \mathrm{mg}^{4}$ has been reported to produce a better quality and a longer duration of motor blockade, as well as a longer duration of analgesia. ${ }^{4}$ On the other hand, better haemodynamic stability has been shown with bupivacaine, ${ }^{3,5}$ which was explained by an insignificantly but consistently lower cephalad spread of sensory and temperature blocks and a less depressed response of plasma catecholamines to the fall in blood pressure. ${ }^{5}$ A lower failure rate has been observed with bupivacaine. ${ }^{2}$

When considering all these studies, some weaknesses appear in their design:

1 population heterogeneity with wide age ranges; 5 
2 different surgical procedures (lower limb or lower abdominal surgery); ${ }^{1-4}$

3 use of single spinal anaesthesia technique, which may necessitate a relative overdosage of drug to cover prolonged surgical procedures;

4 multiple and indirect methods of evaluation of the duration of sensory blockade, i.e., time to regression of two segments ${ }^{2}$ or time to regression to a predetermined sensory level ${ }^{1,2}$ etc .... .

To resolve these discrepancies, we compared the two drugs in a group of geriatric patients undergoing elective total hip remplacement using continuous spinal anaesthesia. This technique may provide more accurate comparisons since it allows the administration of smaller doses of local anaesthetic, ${ }^{6}$ permits the injection of the drug through a catheter in a standardized position, and enables more precise evaluation of the duration of sensory blockade by assessing the time elapsed between the initial injection of drug and the appearance of pain at the operative site during surgery. ${ }^{?}$

\section{Methods}

After institutional approval, informed consent was obtained from 30 patients, older than $75 \mathrm{yr}$, ASA physical status II or III, scheduled for elective total hip replacement under continuous spinal anaesthesia. The patients were randomly allocated into two groups: tetracaine and bupivacaine.

Preoperative medication consisted of meperidine 0.5 $\mathrm{mg} \cdot \mathrm{kg}^{-1}$ and promethazine $0.25 \mathrm{mg} \cdot \mathrm{kg}^{-1}$ im one hour before arrival in the operating room. The ECG was monitored continuously and heart rate and arterial pressures were measured with a noninvasive automatic blood pressure device (Minimap). After an 18 ga peripheral venous catheter was inserted, a central venous line was advanced through the basilic vein under local anaesthesia in all patients. Further invasive monitoring (i.e., indwelling urinary catheter or arterial line) was inserted only if clinically required. Preanaesthetic hydration consisted of $10 \mathrm{ml} \cdot \mathrm{kg}^{-1}$ of a crystalloid solution. Immediately after the injection of the local anaesthetic through the subarachnoid catheter, another $5 \mathrm{ml} \cdot \mathrm{kg}^{-1}$ were administered over the next $30 \mathrm{~min}$. Thereafter perfusions were administered according to changes in arterial pressure, central venous pressure (CVP) and urinary output.

Continuous spinal anaesthesia was performed in the lateral decubitus position. The $\mathrm{L}_{2}-\mathrm{L}_{3}$ or $\mathrm{L}_{3}-\mathrm{L}_{4}$ interspace was punctured with an 18 ga Tuohy needle using the midline approach. A 20 ga catheter was introduced cephalad approximately $4 \mathrm{~cm}$ into the subarachnoid space after free reflux of cerebrospinal fluid was obtained. The patient was then turned to the supine position and the operating table was kept horizontal during the first $30 \mathrm{~min}$ after the injection of the local anaesthetic solution. Thereafter, surgery was performed in the decubitus position.

Patients received through the catheter, in a double-blind fashion, $2 \mathrm{ml}$ of one of the following anaesthetic solutions which were injected at a rate of $1 \mathrm{ml} \cdot \mathrm{min}^{-1}$ :

- Solution 1:

$4 \mathrm{ml}(20 \mathrm{mg}$ ) of bupivacaine $0.5 \%$ in $8 \%$ glucose (Carbostesin $0.5 \%$ hyperbar Astra) diluted with $1 \mathrm{ml}$ of $\mathrm{NaCl} 0.9 \%$, i.e, $5 \mathrm{ml}$ of a hyperbaric solution at $0.4 \%$ (4 $\mathrm{mg} \cdot \mathrm{ml}^{-1}$ ) with a measured density of 1.030 at $37^{\circ} \mathrm{C}$.

- Solution 2:

$2 \mathrm{ml}(20 \mathrm{mg}$ ) of tetracaine $1 \%$ (Pontocaine Winthrop) diluted with $3 \mathrm{ml}$ of $10 \%$ glucose, i.e, $5 \mathrm{ml}$ of a hyperbaric solution at $0.4 \%\left(4 \mathrm{mg} \cdot \mathrm{ml}^{-1}\right)$ with a measured density of 1.030 at $37^{\circ} \mathrm{C}$.

If, $30 \mathrm{~min}$ after the initial $2 \mathrm{ml}$ injection and before surgery, the sensory level did not reach $\mathrm{T}_{10}$ and/or the motor blockade was less than grade 2 on the Bromage scale, ${ }^{8} 1 \mathrm{ml}$ of the same anaesthetic solution was added.

The following variables were assessed every three minutes during the first $30 \mathrm{~min}$ after the injection:

- Upper level of sensory blockade evaluated with the pinprick test.

- Upper level of loss of temperature discrimination, evaluated with ether drops, was considered as the level of sympathetic blockade.

- Quality of bilateral motor blockade according to the Bromage scale: ${ }^{8}$ Grade $0=$ no motor blockade; Grade $1=$ inability to raise extended leg (free movement of feet and knees); Grade 2 = inability to flex knees (able to move feet only); Grade 3 = inability to move feet and knees.

Other variables assessed throughout the procedure were:

- Duration of sensory blockade, which was determined clinically when pain reappeared at the operative site and which prompted the reinjection of $1 \mathrm{ml}$ of the anaesthetic solution;

- When the quality of motor blockade was judged to be insufficient by the surgeon, the patient also received a $1 \mathrm{ml}$ reinjection, but was excluded for determination of the duration of analgesia;

- Variations in systolic, diastolic and mean arterial pressures (MAP) and heart rate, which were measured before the injection, every minute thereafter for the first $15 \mathrm{~min}$ and subsequently every $2.5 \mathrm{~min}$ until the end of the surgery;

- CVP was measured every $15 \mathrm{~min}$ and when a urinary catheter was present, urinary output was measured every $30 \mathrm{~min}$;

- Incidence of clinically important hypotension, defined as a decrease in systolic arterial pressure of more than $30 \%$ from preanaesthetic baseline values, and of bradycardia less than 45 beats $\cdot \mathrm{min}^{-1}$; 
TABLE I Preanaesthetic patient characteristics and haemodynamic data (mean $\pm S D)$

\begin{tabular}{lcc}
\hline & $\begin{array}{l}\text { Bupivacaine } \\
(n=15)\end{array}$ & $\begin{array}{c}\text { Tetracaine } \\
(n=15)\end{array}$ \\
\hline Age (yr) & $80 \pm 5$ & $80 \pm 5$ \\
Weight $(\mathrm{kg})$ & $64 \pm 13$ & $69 \pm 13$ \\
Height $(\mathrm{cm})$ & $163 \pm 4$ & $162 \pm 6$ \\
Female/male & $13 / 2$ & $13 / 2$ \\
ASA status I/III & $6 / 9$ & $5 / 10$ \\
Mean arterial pressure (mmHg) & $99 \pm 9$ & $107 \pm 17$ \\
Heart rate (beats $\cdot$ min $\left.^{-1}\right)$ & $76 \pm 9$ & $78 \pm 17$ \\
Central venous pressure $\left(\mathrm{cm} \mathrm{H}_{2} \mathrm{O}\right)$ & $5 \pm 3$ & $6 \pm 2$ \\
Haematocrit (\%) & $40 \pm 4$ & $40 \pm 4$ \\
\hline
\end{tabular}

- Dosage of vasopressors and/or anticholinergics used;

- Incidence of discomfort and/or anxiety requiring treatment;

- Total volume of crystalloid and blood administered;

- Plasma cathecholamine concentrations determined by a technique previously described., 90 Blood, $10 \mathrm{ml}$, was sampled from the central venous line at four different times: (1) $15 \mathrm{~min}$ after central venous catheter insertion under local anaesthesia and before the insertion of the subarachnoid catheter; (2) $25 \mathrm{~min}$ after injection of the local anaesthetic when maximum decrease in MAP was expected; (3) $85 \mathrm{~min}$ after injection of the local anaesthetic solution during the surgery; (4) just before the first reinjection. All blood samples were collected in prechilled glass tubes and placed immediately on ice. Plasma was separated at $4^{\circ} \mathrm{C}$ and frozen at $-70^{\circ} \mathrm{C}$ for subsequent analysis.

Clinically important hypotension was treated with a 200-250 ml bolus of fluids and ephedrine $5 \mathrm{mg}$ iv which was repeated when necessary. In case of bradycardia atropine sulfate $0.5 \mathrm{mg}$ iv was given. In case of discomfort and/or agitation and anxiety, midazolam 1.5 to $3 \mathrm{mg} i v$ was administered, but only after the first reinjection so as not to interfere with duration of analgesia.

The incidence of postdural puncture headache as well as other complications were noted.

All results are expressed as mean values $\pm \mathrm{SD}$ or median (range) for ordinal data. The two groups of patients were compared using an unpaired t test, MannWhitney $U$ test, analysis of variance or Chi square as required. A $P$ value 0.05 was considered as statistically significant.

\section{Results}

Fifteen patients were allocated to each group. The patients' characteristics, ASA physical status, as well as preanaesthetic haemodynamic data and haematocrit were comparable in both groups (Table I).

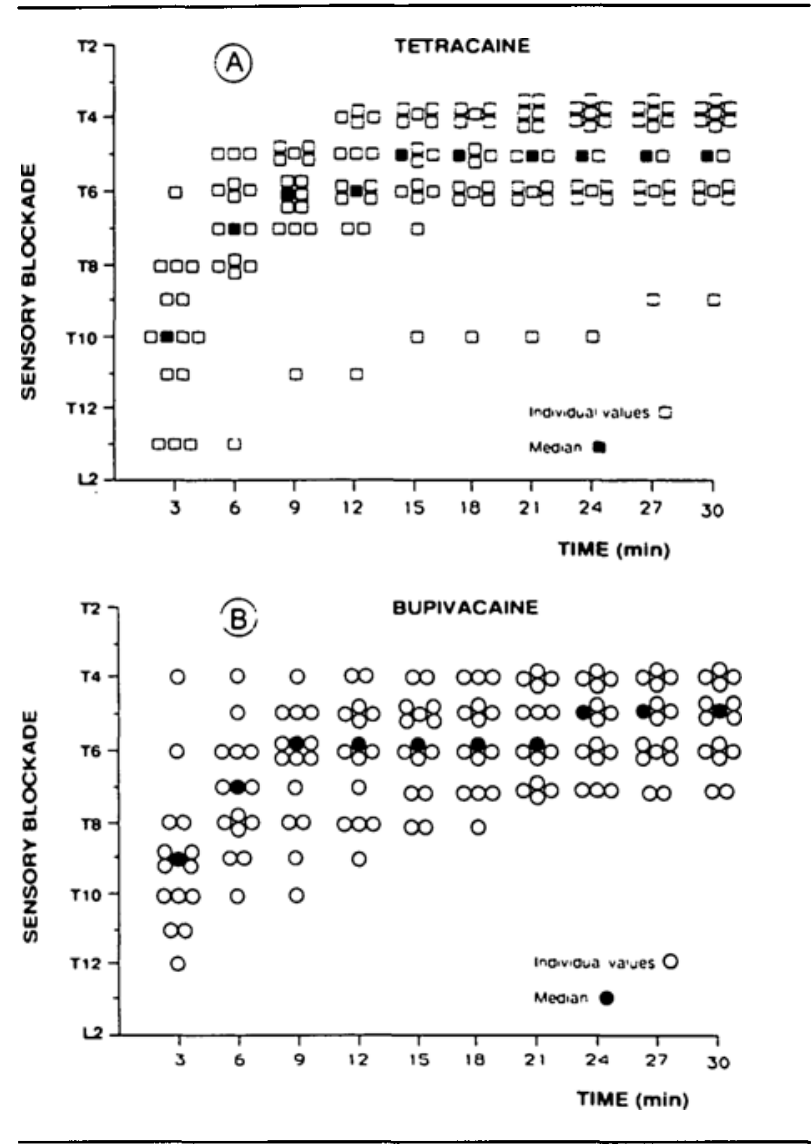

FIGURE 1 Comparison of the progression of sensory level between tetracaine (A) and bupivacaine (B) during the first $30 \mathrm{~min}$. (Individual values shown as open squares and circles; median value is shown as full squares or circles; $n=15$ for each group).

\section{Sensory blockade}

The cephalad progression of sensory blockade within the first $30 \mathrm{~min}$ after the intrathecal injection is illustrated in Figure 1. No differences in this level were observed at any time between the two groups. The median highest sensory levels observed were $T_{5}$ for both bupivacaine (range $T_{5}$ $\mathrm{T}_{9}$ ) and tetracaine (range $\mathrm{T}_{5}-\mathrm{T}_{9}$ ) and were obtained in a comparable time, $16 \pm 8 \mathrm{~min}$ and $15 \pm 5 \mathrm{~min}$ respectively.

\section{Temperature discrimination level}

The median highest level of loss of temperature discrimination was $\mathrm{T}_{4}$ for both drugs. This level was also obtained in a comparable time, i.e, $17 \pm 6 \mathrm{~min}$ for bupivacaine and $13 \pm 6 \mathrm{~min}$ for tetracaine. The cephalad progression of this level was parallel to the progression of the sensory level, except that it was at all times one dermatome higher.

\section{Motor blockade}

The evolution of the number of patients with a motor 


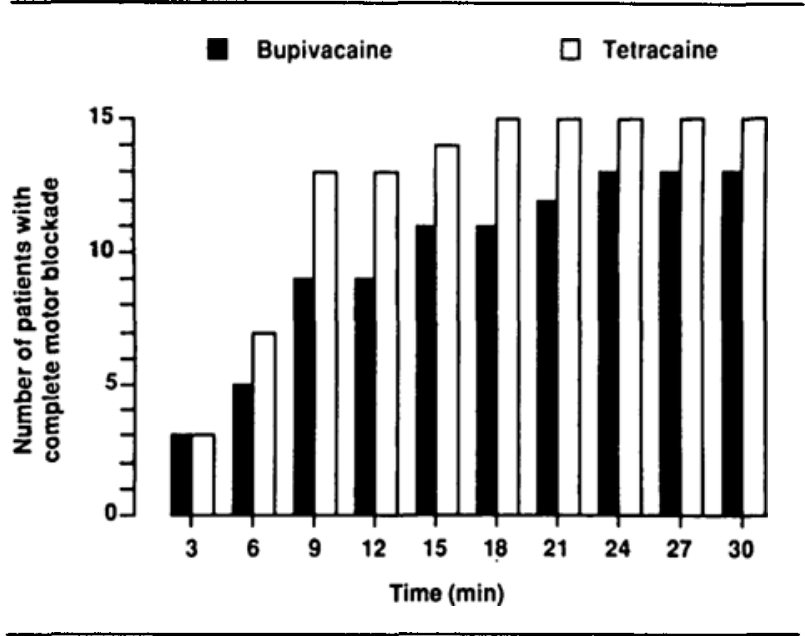

FIGURE 2 Comparison of the number of patients with complete motor blockade during the first $30 \mathrm{~min}$ after administration of hyperbaric bupivacaine and tetracaine ( $n=15$ for each group).

blockade of grade 3 during the first $30 \mathrm{~min}$ is illustrated in Figure 2. No differences were observed at any time between the two groups. The mean time to induce such a blockade was $10 \pm 7 \mathrm{~min}$ with bupivacaine and $8 \pm 4 \mathrm{~min}$ with tetracaine. Thirty minutes after the initial spinal injection, two patients in the bupivacaine group required additional drug because of inadequate motor blockade. Likewise, during the surgical procedure, two patients receiving bupivacaine and one patient receiving tetracaine were judged by the surgeons as having poor motor blockade and were given an additional $\mathrm{ml}$ of drug. These five patients were not considered for determination of the duration of analgesia.

\section{Duration of sensory blockade}

Except for the five patients previously mentioned which were excluded, the duration of analgesia was comparable for both drugs and averaged $114 \pm 23 \mathrm{~min}$ for bupivacaine $(n=11)$ and $125 \pm 35$ min for tetracaine $(n=14)$. In addition, because of prolonged surgery eight bupivacaine and 12 tetracaine patients received a second reinjection, and four patients in each group a third reinjection of $1 \mathrm{ml}$ of local anaesthetic. The different intervals separating the injections and reinjections are presented in Table II. The delay between injections was longer for tetracaine only between the second and the third reinjection $(P<0.05)$.

\section{Haemodynamic changes}

During the first $30 \mathrm{~min}$ after injection of the anaesthetic solution, the mean changes in MAP and heart rate, the coefficient of variation of both values as well as number of patients given ephedrine and its mean total dosage are reported in Table III. No significant differences between
TABLE II Duration of analgesia and time intervals between injections (mean $\pm \mathrm{SD}$ )

\begin{tabular}{llc}
\hline & Bupivacaine & Tetracaine \\
\hline $\begin{array}{l}\text { Time (min) between initial } \\
\text { injection }(8 \mathrm{mg}) \text { and first }\end{array}$ & $\begin{array}{l}114 \pm 23 \\
(n=11)\end{array}$ & $\begin{array}{l}125 \pm 35 \\
(n=14)\end{array}$ \\
$\begin{array}{l}\text { reinjection (4 mg) } \\
\text { Time (min) between first } \\
\text { reinjection (4 mg) and second } \\
\text { reinjection (4 mg) }\end{array}$ & $\begin{array}{c}72 \pm 20 \\
(n=8)\end{array}$ & $\begin{array}{c}88 \pm 28 \\
(n=12)\end{array}$ \\
$\begin{array}{l}\text { Time (min) between second } \\
\text { reinjection (4 mg) and third } \\
\text { reinjection (4 mg) }\end{array}$ & $59 \pm 9$ & $85 \pm 18 *$ \\
\hline$* P<0.05$. & & $(n=4)$
\end{tabular}

TABLE III Haemodynamic changes during the first 30 min after initial injection of local anaesthetic (mean \pm SD)

\begin{tabular}{lcc}
\hline & $\begin{array}{l}\text { Bupivacaine } \\
n=15\end{array}$ & $\begin{array}{l}\text { Tetracaine } \\
n=15\end{array}$ \\
\hline $\begin{array}{l}\text { Maximal changes (\%) from } \\
\quad \text { preanaesthetic values in MAP }\end{array}$ & $-25 \pm 10$ & $-31 \pm 13$ \\
Observed after (min): & $16 \pm 9$ & $16 \pm 8$ \\
Coef. var. (\%)for MAP & $7.3 \pm 3.6$ & $9.2 \pm 3.8$ \\
$\begin{array}{l}\text { Maximal changes (\%) from } \\
\text { preanaesthetic values in HR }\end{array}$ & $-9 \pm 9$ & $-10 \pm 9$ \\
$\begin{array}{l}\text { Observed after (min): } \\
\text { Coef. var. (\%) for HR }\end{array}$ & $20 \pm 6$ & $18 \pm 7$ \\
Number of patients & $6.9 \pm 4.4$ & $6.5 \pm 2.6$ \\
$\quad$ receiving ephedrine & 8 & 9 \\
Mean dosage (mg) of ephedrine & $15 \pm 9$ & $17 \pm 17$ \\
\hline
\end{tabular}

MAP $=$ mean arterial pressure. $\mathrm{HR}=$ heart rate. Coef. var. $=$ Coeffi cient of variation.

the two groups were observed. One patient in the bupivacaine group required $0.5 \mathrm{mg}$ of atropine sulfate to treat bradycardia.

\section{Plasma catecholamines}

Plasma concentrations of epinephrine and norepinephrine, obtained at four different times during the study, are illustrated in Figure 3. No differences were observed either between the two groups or among the four values in the same group. No correlation was found among the cathecholamine levels obtained at $25 \mathrm{~min}$ and the maximal height of loss of temperature discrimination, maximal sensory levels, or maximal decrease in MAP.

During the surgical procedure which lasted $167 \pm 40$ $\mathrm{min}$ in the bupivacaine group and $191 \pm 70 \mathrm{~min}$ in the tetracaine group (NS), mean values of MAP, heart rate, CVP ( $n=15$ in each group) and urinary output ( $n=11$ for tetracaine and $n=9$ for bupivacaine) were comparable in the two groups at all times. Crystalloid administration averaged $2500 \pm 575 \mathrm{ml}$ and $2700 \pm 1100 \mathrm{ml}(\mathrm{NS})$, and blood administration reached $1000 \pm 400 \mathrm{ml}$ and $1100 \pm$ 


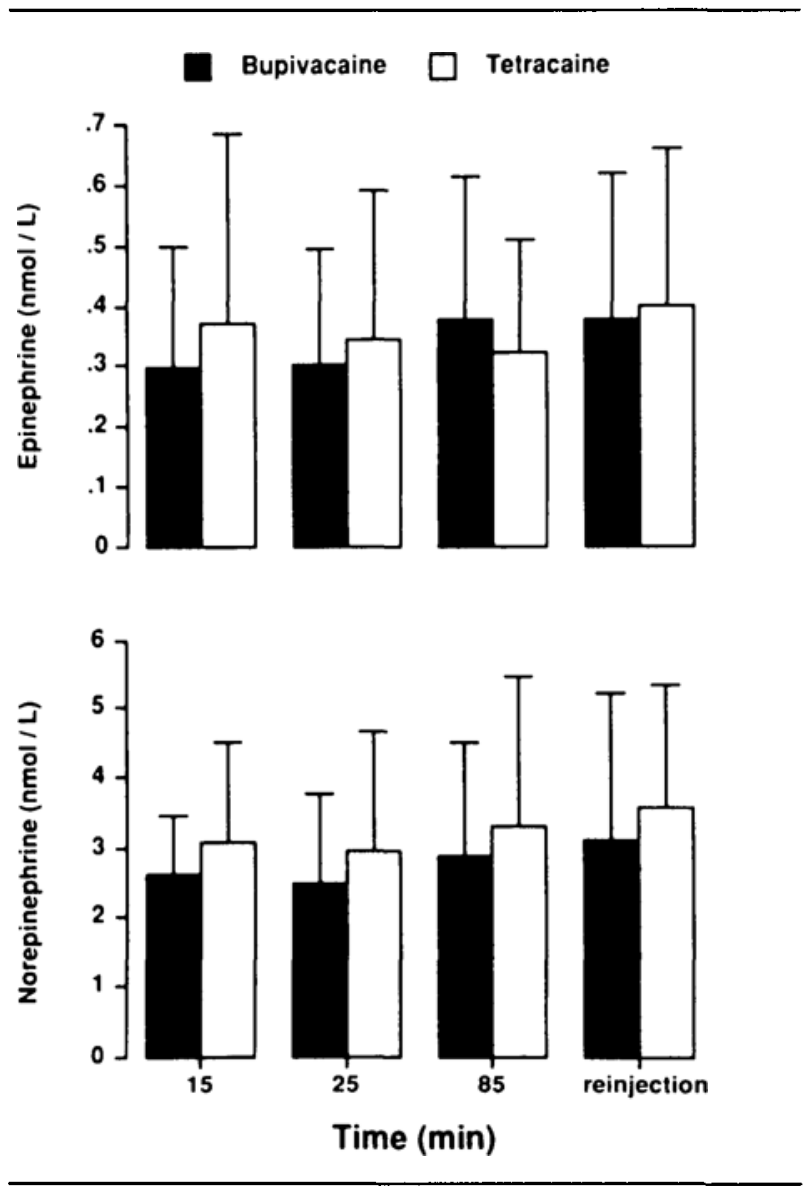

FIGURE 3 Comparison of plasma epinephrine and norepinephrine concentrations between the two groups, measured at four different times (mean $\pm \mathrm{SD} ; n=15$ for each set of measurements, except for reinjection time of bupivacaine where $n=13$ ).

$540 \mathrm{ml}$ respectively (NS). A comparable number of patients in both groups (seven bupivacaine and five tetracaine) received midazolam (mean dose $4 \mathrm{mg}$ ) for sedation. No anaesthetic failure was observed with any of the two drugs.

One patient in the bupivacaine group developed a postspinal headache which lasted $48 \mathrm{hr}$ and resolved with conservative treatment.

\section{Discussion}

This study compared, at the same dose $(8 \mathrm{mg})$ and the same volume $(2 \mathrm{ml})$, hyperbaric solutions of bupivacaine and tetracaine of identical density (1.030) during continuous spinal anaesthesia in a group of elderly patients undergoing identical surgical procedures. The results did not reveal any difference between the anaesthetic and haemodynamic effects of these two drugs. Since this was the first comparison of hyperbaric bupivacaine and tetracaine during continuous spinal anaesthesia our results will be discussed and compared with studies investigating identical dosage and volume of these two drugs during hyperbaric single-shot spinal anaesthesia. Among these reports, two have compared $7.5 \mathrm{mg}$ of bupivacaine and tetracaine ${ }^{1,2}$ which is similar to the dose used in the present study. Comparison of these two drugs at higher doses such as $9.75 \mathrm{mg},{ }^{1} 12 \mathrm{mg}^{2}$ and $15 \mathrm{mg}^{1,3-5}$ have also been reported.

In the present study the maximal sensory levels and the time to reach these levels were comparable for both drugs. Similar results have been reported by Pflug $^{1}$ and Moore $^{2}$ using $7.5 \mathrm{mg}$ of the 2 drugs. Using higher doses $(15 \mathrm{mg}$ ) of either drug, Rocco ${ }^{4}$ demonstrated a significantly higher cephalad spread with bupivacaine whereas Biggler ${ }^{5}$ reported a consistently though insignificantly higher sensory blockade with tetracaine.

There is no single reliable method of assessing the duration of sensory blockade. Different criteria such as regression of sensory level by two segments, ${ }^{2,11}$ regression to $\mathrm{T}_{10}{ }^{12} \mathrm{~T}_{12}{ }^{3} \mathrm{~L}_{1}{ }^{1,11} \mathrm{~L}_{2}{ }^{13}, \mathrm{~L}_{5}{ }^{3}$ or complete sensory recovery ${ }^{1,4,5,14,15}$ have been used. Moore ${ }^{2,16}$ suggested that, during the postoperative period, the appearance of pain on the operative site was the best method of assessing the duration of spinal analgesia. In our study, we used a similar method. ${ }^{7}$ The precision of this criterion is further enhanced as the position of the operating table and surgical incisions were identical in all patients. The results indicate that the duration of sensory blockade was comparable for both groups which is in agreement with other studies, ${ }^{1-3}$ but not with the findings of Rocco ${ }^{4}$ who reported that the time of total regression of sensory anaesthesia was longer with $15 \mathrm{mg}$ of hyperbaric tetracaine than with the same dose of bupivacaine. The number of patients requiring reinjections because of intraoperative pain and time intervals is reported in Table II. The time separating the second and third reinjection (after a total dose of $8+4 \mathrm{mg}$ ) appears to be longer for tetracaine. However, because of the small number of patients, this trend does not allow any conclusions on the possibly longer duration of sensory blockade with tetracaine.

Moore has reported ${ }^{2}$ that the quality of sensory blockade obtained with hyperbaric bupivacaine was better than that obtained with hyperbaric tetracaine since additional analgesia was required in only one of 121 patients receiving $7.5 \mathrm{mg}$ of bupivacaine compared with 19 of 114 patients receiving $7.5 \mathrm{mg}$ of tetracaine. Other studies suggested also that bupivacaine produced a more profound sensory blockade. ${ }^{3,4}$ Our results differ from these findings, since $30 \mathrm{~min}$ after the initial injection, the quality of sensory anaesthesia was judged to be adequate in all patients. Furthermore, the skin incision was painless in all patients and the duration of anaesthesia was similar for both drugs. It is difficult to explain these differences. 
Nevertheless, it must be noted that previous investigations were conducted using single-shot spinal anaesthesia where the possibility of technical failure such as incomplete injection of local anaesthetic into the subarachnoid space should be always considered. Despite rare reports of cases of subdural catheter placement, ${ }^{17,18}$ this is unlikely to occur during continuous spinal anaesthesia since the catheter is introduced at last $4 \mathrm{~cm}$ into the subarachnoid space and its position can be confirmed by repeated aspiration of cerebrospinal fluid throughout surgery.

The median maximal level of loss of temperature discrimination was identical for both drugs and was about one dermatome higher than the median sensory level. Biggler ${ }^{5}$ reported a similar observation with $15 \mathrm{mg}$ of either drug. These results have been confirmed by a recent report where equipotent doses of bupivacaine $0.75 \%$ in $8.25 \%$ dextrose and tetracaine $0.5 \%$ in $5 \%$ dextrose were compared. ${ }^{19}$

It has been shown that hyperbaric tetracaine $7.5 \mathrm{mg},{ }^{2}$ $9.75 \mathrm{mg}^{1}$ and $15 \mathrm{mg}^{3}$ produced a greater motor blockade than identical doses of hyperbaric bupivacaine. In addition, the time to obtain the maximum degree of motor blockade was shorter with tetracaine $12 \mathrm{mg} .{ }^{2}$ These findings were not confirmed in the present study where $8 \mathrm{mg}$ of either drug produced, after a comparable time, a complete motor blockade in 13 out of 15 bupivacaine patients and 15 out of 15 tetracaine patients. In order to avoid interference with surgery, the duration of motor blockade was not assessed in the present study. However, two patients receiving bupivacaine and one who received tetracaine were given the first reinjection because the surgeon judged the motor blockade to be insufficient. Previous investigations reporting longer duration of motor blockade for hyperbaric tetracaine $7.5 \mathrm{mg}^{2} 12 \mathrm{mg}^{2}$ and $15 \mathrm{mg}^{4}$ can neither be confirmed nor denied.

The mean maximal decrease in MAP, which occurred $16 \mathrm{~min}$ after the initial injection, was comparable in both groups of patients. Comparing $15 \mathrm{mg}$ of either drug, Rocco ${ }^{4}$ found similar results, whereas at the same dose Biggler ${ }^{5}$ and Gielen $^{3}$ reported greater degrees of hypotension in patients receiving hyperbaric tetracaine. The changes in heart rate were not different and this is in agreement with others., ${ }^{3,5}$

Plasma concentrations of epinephrine and norepinephrine were measured at four different times. No changes were observed among the four values measured in the same group or between the corresponding values of the two groups (Figure 3). On the contrary, Biggler ${ }^{5}$ found that in younger subjects (mean age $54 \mathrm{yr}$ ), at the time of maximal decrease in MAP (20 minutes after spinal injection), there was an increase from baseline values of norepinephrine in patients receiving bupivacaine and a decrease from baseline values of epinephrine in patients receiving tetracaine; the difference in catecholamine levels between the two groups was not significant. In another study ${ }^{20}$ where patients with high $\left(\mathrm{T}_{2}-\mathrm{T}_{6}\right)$ and low $\left(\mathrm{T}_{9}-\mathrm{T}_{12}\right)$ sensory levels were compared during hyperbaric tetracaine spinal anaesthesia, decreases from preanaesthetic values in plasma epinephrine and norepinephrine concentrations were observed after 30 min only in patients with a high level of blockade. Our data are not in agreement with these reports, since with the same baseline values of plasma catecholamine concentrations and comparable sensory levels, no changes in plasma epinephrine and norepinephrine were observed. It is difficult to explain these contradictory findings.

No anaesthetic failure nor relevant side-effects were observed in the present study which confirmed the reliability and safety of continuous spinal anaesthesia for lower limb surgery in elderly patients as reported previously by our institution. ${ }^{6}$ Only one patient suffered from a mild postspinal headache. This observation confirms the very low incidence of this complication despite the use of large diameter spinal needles. ${ }^{7,21}$

In summary, our data demonstrate that equipotent solutions of hyperbaric bupivacaine and tetracaine have similar anaesthetic and cardiovascular effects. Previous investigations comparing these two drugs during single-shot spinal anaesthesia have reported clinical differences, which varied among studies. The differences between the present study and previous reports can probably be explained because our study addressed a more selected population undergoing identical surgery, and using the continuous spinal anaesthesia technique. We believe that this technique, by administrating reduced doses of local anesthetics, should have allowed an easier identification of any relevant differences between the two drugs studied, which was not the case. However, we are aware that the study of drugs in 80-yr-old patients is not representative of the general population of surgical patients.

\section{Acknowledgement}

The authors would like to thank Mr. Julien Lopez for his excellent technical assistance.

\section{References}

1 Pflug AE, Aasheim GM, Beck HA. Spinal anesthesia: bupivacaine versus tetracaine. Anesth Analg 1976; 55: 489-92.

2 Moore DC. Spinal anesthesia: bupivacaine compared with tetracaine. Anesth Analg 1980; 59: 743-50.

3 Gielen MJM, de Grood PMRM, Edstrom HH, Crul $J F$. Comparison of bupivacaine and tetracaine for spinal anesthesia. Regional Anesthesia 1984; 9: 62-7.

4 Rocco AG, Mallampati SR, Boon J, Concepcion M, Horowitz AM. Double blind evaluation of intrathecal 
bupivacaine and tetracaine. Regional Anesthesia 1984; 9: 183-7.

5 Biggler D, Hjortso NC, Edström HH, Christensen NJ, Kehlet $H$. Comparative effects of intrathecal bupivacaine and tetracaine on analgesia, cardiovascular function and plasma catecholamines. Acta Anaesthesiol Scand 1986; 30: 199-203.

6 Sutter PA, Gamulin Z, Forster A. Comparison of continuous spinal and continuous epidural anesthesia for lower limb surgery in elderly patients. A retrospective study. Anaesthesia 1989; 44: 47-50.

7 Van Gessel EF, Forster A, Gamulin Z. Surgical repair of hip fractures using continuous spinal anesthesia: comparison of hypobaric solutions of tetracaine and bupivacaine. Anesth Analg 1989; 68: 276-81.

8 Bromage $P R$. A comparison of the hydrochloride and carbon dioxide salts of lidocaine and prilocaine in epidural analgesia. Acta Anaesthesiologica Scandinavica (suppl.) 1965; 16: 55-69.

9 Bouloux P, Perrett D, Besser GM. Methodological considerations in the determination of plasma catecholamines by high-performance liquid chromatography with electrochemical detection. Ann Clin Biochem 1985; 22: 194-203.

10 Causon RC, Brown MJ, Bouloux PM. Analytical differences in measurement of plasma catecholamines. Clin Chem 1983; 29: 735-6.

11 Tuominen $M$, Pitkänen $M$, Doepel $M$, Rosenberg $P H$. Spinal anaesthesia with hyperbaric tetracaine: effect of age and body mass. Acta Anaesthesiol Scand 1987; 31: 474-8.

12 Rocco AG, Francis DM, Wark JA, Concepcion MA, Covino $B G$. A clinical double blind study of dibucaine and tetracaine in spinal anesthesia. Anesth Analg 1982; 61: 133-7.

13 Bonnet F, Brun-Buisson V, Saada M, Boico O, Rostaing S, Touboul $C$. Dose-related prolongation of hyperbaric tetracaine spinal anesthesia by clonidine in humans. Anesth Analg 1989; 68: 619-22.

14 Chambers WA, Littlewood DG, Edstrom HH, Scott $D B$. Spinal anaesthesia with hyperbaric bupivacaine: effects of concentration and volume administered. $\mathrm{Br} \mathrm{J}$ Anaesth 1982; 54: 75-82.

15 Sundnes $K O$, Vaagenes $P$, Skretting $P$, Lind $B$, Edström $H H$. Spinal analgesia with hyperbaric bupivacaine: effects of volume of solution. Br J Anaesth 1982; 54: 69-74.

16 Moore DC, Chadwick HS, Ready LB. Epinephrine prolongs lidocaine spinal: pain in the operative site the most accurate method of determining local anesthetic duration. Anesthesiology 1986; 67: 416-8.
17 Mocan M, Gamulin Z, Klopfenstein CE, Forster $A$. Catheterisme accidentel de l'espace sous dural: complication de la rachianesthésie continue et de l'anesthésie peridurale continue. Can J Anaesth 1989; 36: 708-12.

18 Stevens RA, Stanton-Hicks $M d$ 'A. Subdural injection of local anesthetic: a complication of epidural anesthesia. Anesthesiology 1985; 63: 323-6.

19 Brull SJ, Greene NM. Time-courses of zones of differential sensory blockade during spinal anesthesia with hyperbaric tetracaine or bupivacaine. Anesth Analg 1989; 69: 342-7.

20 Pflug $A E$, Halter $J B$. Effect of spinal anesthesia on adrenergic tone and the neuroendocrine responses to surgical stress in humans. Anesthesiology 1981; 55: 120-6.

21 Denny N, Master R, Pearson D, Read J, Sihota M, Selander $D$. Postdural puncture headache after continuous spinal anesthesia. Anesth Analg 1987; 66: 791-4. 